\title{
Corticosteroids for spontaneous intracranial hypotension: a case-report and critical review focusing on pathophysiology and treatment
}

\author{
Efthalia Angelopoulou ${ }^{1 *}$ (D) Eirini Pantou ${ }^{2}$, Georgios Zacharis ${ }^{1}$, Michail Rentzos $^{1}$, Leonidas Stefanis ${ }^{1}$ and
} Vasiliki Zouvelou ${ }^{1}$

\begin{abstract}
Background: Spontaneous intracranial hypotension $(\mathrm{SIH})$ is characterized by positional headache caused by low CSF pressure, without any major traumatic event. Optimal treatment is still debated; epidural blood patch (EBP) is usually used after unsuccessful conservative treatment with variable efficacy and potentially severe complications. Although steroids have been reported to be beneficial, their effectiveness is still controversial, and more clinical evidence is needed.

Case presentation: A 37-year-old woman was admitted to the neurology department due to severe orthostatic headache with nausea over the last 5 days. No trauma history or spinal manipulation were mentioned. On arrival, neurological examination, brain $\mathrm{CT}$, and laboratory investigation were normal. Intracranial hypotension was clinically suspected, and lumbar puncture revealed low opening pressure. Brain MRI demonstrated pachymeningeal gadolinium enhancement and distended and rounded dural venous sinuses, while cervicothoracic spine MRI revealed thoracic CSF leakage, leading to SIH diagnosis. The patient was treated with high-dose intravenous methylprednisolone, with complete clinical resolution within $24 \mathrm{~h}$.

Conclusions: Our case, combined with literature evidence, supports the high-dose intravenous corticosteroids as a reasonable treatment option in selected cases, before trying EBP or surgical repair. Randomized clinical trials are needed, in order to optimize SIH patients' outcomes.
\end{abstract}

Keywords: SIH, CSF leakage, Epidural blood patch, Corticosteroids, Headache

\section{Background}

Spontaneous intracranial hypotension $(\mathrm{SIH})$ is a wellrecognized but underdiagnosed condition caused by low cerebrospinal fluid (CSF) pressure without any major proceeding traumatic event, typically presenting with positional headache $[1,2]$. Brain and spinal magnetic resonance imaging (MRI) may reveal pachymeningeal enhancement and the CSF leakage into the epidural

\footnotetext{
* Correspondence: angelthal@med.uoa.gr

${ }^{1}$ Department of Neurology, National and Kapodistrian University of Athens,

Eginition Hospital, Leof. Vasilissis Sofias 72, 11528 Athens, Greece

Full list of author information is available at the end of the article
}

space respectively, and lumbar puncture usually confirms the low CSF pressure. Therapeutic options involve conservative treatment with bed rest and hydration and autologous epidural blood patch (EBP), while the use of corticosteroids still remains debated. Given the controversies on therapeutic approach and the lack of guidelines and randomized clinical trials, treatment decisions are often difficult and they are predominantly based on clinical observations $[1,3]$.

Herein, we describe a case of a 37-year-old woman presenting with severe orthostatic headache, finally attributed to SIH. Her symptoms were completely resolved 
after high-dose intravenous corticosteroid treatment. Next, we provide an updated review on the epidemiology, pathophysiology, diagnosis, clinical presentation, and treatment options for $\mathrm{SIH}$, focusing on steroid therapy. Combined with available literature evidence, we suggest that this therapeutic option should be considered in selected refractory cases and should be included in future randomized controlled trials for this condition.

\section{Case presentation}

A 37-year-old woman visited our neurology emergency department due to episodes of new-onset severe positional pressure-like headache localized in the occipital and frontal region, accompanied by nausea without vomiting over the last 5 days. Characteristically, the headache episodes worsened in the upright or sitting position and dramatically improved upon recumbency, while there was no relief with common nonsteroidal anti-inflammatory drugs (NSAIDs). Onset of headache was gradual, reaching its highest intensity in several minutes. No trauma history, spinal manipulation, recent medical procedure like lumbar puncture, fever, or any recent illness were reported. The patient did not mention visual disturbances, photophobia or any other complaints. Her past medical history including history of headaches was unremarkable, and family history was negative for any neurological disorder. On arrival, the patient was alert and her vital signs were normal (blood pressure $110 / 70 \mathrm{mmHg}$, pulse 82 beats $/ \mathrm{min}$, temperature $36.9^{\circ} \mathrm{C}$, oxygen saturation $99 \%$ ). She was pain-free and in no distress in the supine position, but very uncomfortable when standing upright. There was moderate discomfort on passive neck flexion, whereas no signs of meningeal irritation (neck stiffness, Kerning and Brudzinski signs) were elicited. Neurological examination revealed round and reactive to light pupils, normal cranial nerves II-XII and deep tendon reflexes, flexion plantar reflexes, as well as no visual field, cerebellar, sensation, or motor deficits. Based on her presentation, with the clear positional effect on headache intensity, SIH was clinically suspected.

Laboratory investigation, including complete blood count, routine biochemical analysis, erythrocyte sedimentation rate, coagulation testing, thyroid function, and arterial blood gas test, was unremarkable. The patient underwent brain computed tomography (CT) scan without contrast, which was normal. Lumbar puncture revealed low opening pressure $\left(50 \mathrm{~mm} \mathrm{H}_{2} \mathrm{O}\right.$, normal values $70-180 \mathrm{~mm} \mathrm{H}_{2} \mathrm{O}$ ), and CSF examination indicated normal white blood cell count $\left(5 \mathrm{WBC} / \mathrm{mm}^{3}\right.$, normal values $0-8 \mathrm{WBC} / \mathrm{mm}^{3}$ ), no red blood cells, no xanthochromia, normal glucose of $59 \mathrm{mg} / \mathrm{dL}$ (serum glucose $77 \mathrm{mg} / \mathrm{dL}$ ), and normal protein levels $(34 \mathrm{mg} / \mathrm{dL}$, normal values $15-45 \mathrm{mg} / \mathrm{dL}$ ). Gram's stain, culture, and
PCR panel (Borrelia burgdorferi, Cryptococcus neoformans, Haemophilus influenzae, Listeria monocytogenes, Neisseria meningitidis, Streptococcus agalactiae, Streptococcus pneumoniae, HSV-I, HSV-II, EBV, CMV, VZV, Enterovirus, Parechovirus) of the CSF were also negative.

The patient was subjected to MRI of the brain with gadolinium, which demonstrated intense pachymeningeal supra- and infratentorial bilateral enhancement, without subdural effusions or tonsillar herniation. Dural venous sinuses were distended and rounded, without any signs of thrombosis. Mild reduction of suprasellar cistern was also reported; pituitary gland was $7 \times 10 \mathrm{~mm}$ in diameter with convex superior margin (Fig. 1). MRI scan of cervical and thoracic spine revealed fluid collection in the posterior epidural space at the T2-T10 thoracic vertebra level, causing mild compression of the spinal cord anteriorly. Pachy- and leptomeningeal enhancement was also identified in the whole thoracic spinal cord, especially at the T2-T10 level, with a length about $5 \mathrm{~cm}$. At this level, "floating dural sac sign" was also noted, and CSF leakage was strongly suspected. Collectively, the abovementioned neuroimaging findings were highly indicative of intracranial hypotension accompanied by CSF leakage at the thoracic T2-T10 level.

Based on the medical history, clinical presentation, low CSF opening pressure, and neuroimaging findings, the diagnosis of SIH with thoracic CSF leakage was made. The patient was treated with bed rest, IV hydration, and paracetamol with no clinical improvement. Due to persistent headache, IV methylprednisolone $(500 \mathrm{mg} /$ day $)$ was administered for three consecutive days, following tapering with p.o. methylprednisolone for totally 15 days. On the 1st day (about $20 \mathrm{~h}$ ) after the initiation of corticosteroids, her headache and nausea started to significantly improve, whereas on the 3rd day her symptoms were almost completely resolved. No adverse events were observed. The patient was discharged 3 days later without headache, in excellent neurological condition. At the follow-up 1 month later, the patient remained asymptomatic.

\section{Discussion}

Herein, we presented a case of a 37-year-old woman complaining of severe orthostatic headache over the last 5 days, attributed to $\mathrm{SIH}$, accompanied by thoracic CSF leakage. Her symptoms were completely resolved after high-dose IV corticosteroid treatment. Next, we provide a brief updated review regarding the epidemiology, pathophysiology, clinical presentation, diagnosis, and treatment options for this entity, focusing on steroid therapy, as well as further discuss our case. We systematically searched the literature in "PUBMED" for casereports, case-series and reviews investigating and discussing the abovementioned aspects of $\mathrm{SIH}$, published 


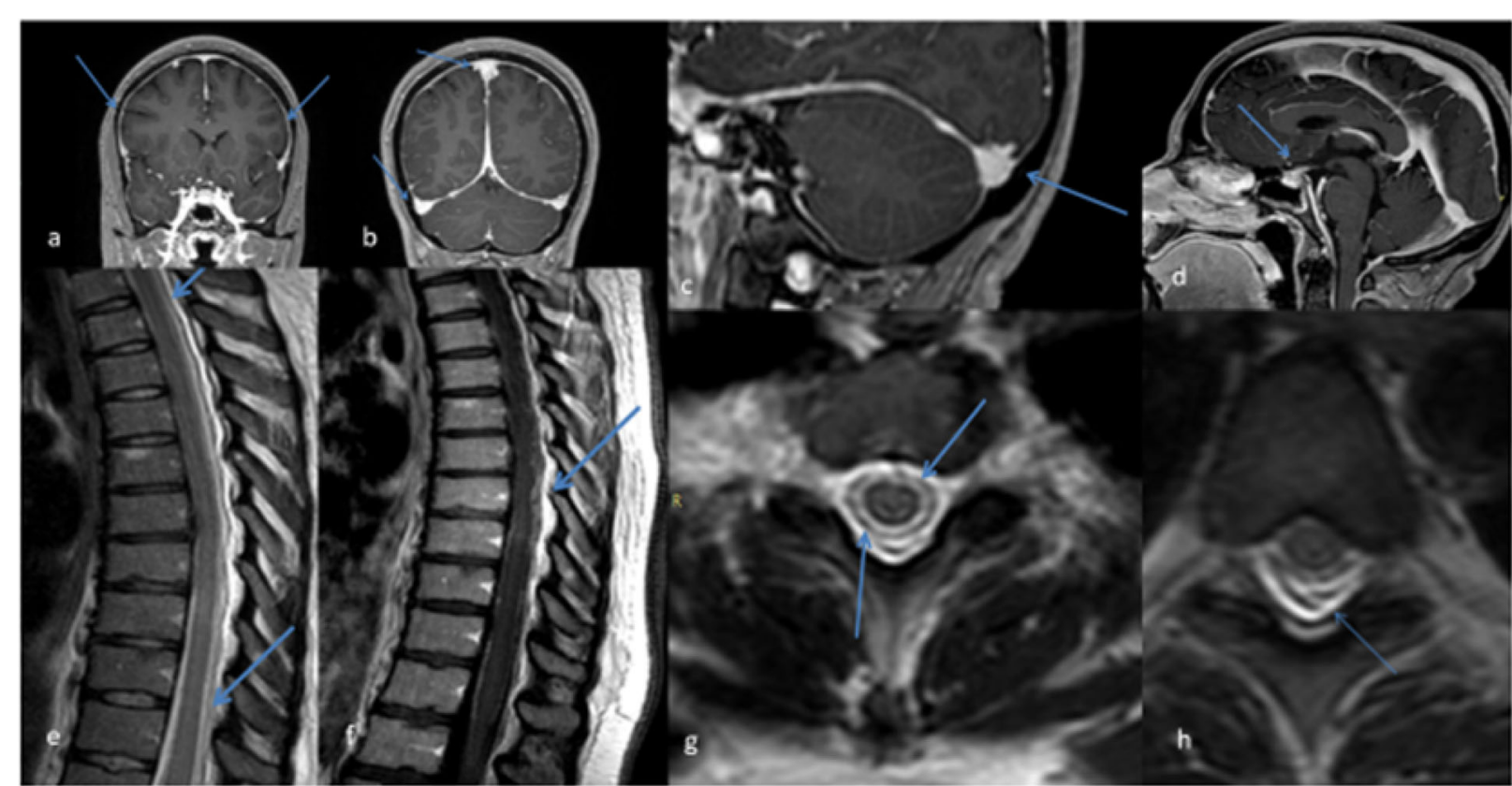

Fig. 1 MRI of the brain and thoracic spine of the patient with spontaneous intracranial hypotenstion. a Coronal contrast-enhanced T1-weighted brain MRI image showing pachymeningeal gadolinium enhancement (blue arrows). b Coronal contrast-enhanced T1-weighted brain MRI image demonstrating distended and rounded dural venous sinuses (blue arrows). c Sagittal contrast-enhanced T1-weighted brain MRI image indicating venous distension sign (rounding of the cross-section of the dural venous sinuses, blue arrow). $\mathbf{d}$ Sagittal contrast-enhanced T1-weighted brain MRI image showing mild reduction of suprasellar cistern and enlargement and hyperemia of the pituitary gland (blue arrow). e Sagittal and T2weighted MRI of the thoracic region showing dorsal fluid collection in the sub/epidural space at the T2-T10 thoracic vertebra level, causing mild compression of the spinal cord anteriorly (blue arrows). $\mathbf{f}$ Midline sagittal contrast-enhanced T1-weighted MRI image of the thoracic region demonstrating marked enhancement of thickened pachyleptomeninges and dilated epidural veins especially at the T6-T8 level (blue arrows). g A hyperintense band or rim around the spinal thecal sac in axial T2-weighted MRI image at the thoracic level (blue arrows), suggestive of CSF leak. h Axial T2-weighted MRI image at T5 level, showing the "floating dural sac sign" (blue arrows)

from 1950 to March of 2020, using the terms "intracranial hypotension," "steroids," "corticosteroids," "treatment," "SIH," "orthostatic headache," "postural headache," "CSF leak," and "CSF leakage" in various combinations.

\section{Epidemiology}

$\mathrm{SIH}$ is not as rare as previously considered [4]. Solid community-based epidemiological data are lacking [5], and the condition may be often underdiagnosed especially in local primary healthcare centers, given its relatively broad differential diagnosis $[1,6]$. Its incidence is estimated $2-5 / 100,000$ per year $[1,3,7,8]$, and in the emergency department, it has been reported to account for $0.5-1 \%$ of all headaches [8]. SIH typically occurs between the 4th and 6th decade of life, but it can also manifest in children and the elderly [1, 3]. It affects women about two to five times more often than men [3, 9]. SIH develops without any obvious preceding event causative of CSF leakage; however, both hereditary and acquired risk factors may contribute to its occurrence [7]. Connective tissue disorders, including Ehlers-Danlos type II and Marfan syndrome, as well as autosomal dominant polycystic kidney disease, Lehman syndrome, and neurofibromatosis type $\mathrm{I}$, have been associated with $\mathrm{SIH}$, which sometimes presents the initial manifestation of the genetic disease [1,9-11]. Excessive and rapid weight loss after bariatric surgery [12], short stature [13], and malnutrition [14] have been also reported as a potential risk factors for this condition.

\section{Pathophysiology}

While CSF leakage via weak dural sites into the epidural space is the predominant mechanism underlying $\mathrm{SIH}$, the exact etiology and pathophysiological processes remain obscure [1]. Meningeal structural fragility could play a role [2], and minor traumatic events like weight lifting or intense coughing may precipitate the leakage [11, 15]. Extradural pathologies like a congenital osseous spur or acquired degenerative disc disorder are some other potential causes [4, 11]. Abnormal elastin and fibrillin leading to increased dural permeability may underlie $\mathrm{SIH}$ development in connective tissue disorders $[2,16]$. Decreased CSF secretion or increased CSF absorption have not been proven to be etiologically associated with this condition [11]. A reduced CSF volume and not CSF pressure has been suggested to 
underlie SIH pathophysiology; thus, the term "spontaneous CSF hypovolemia" has been used interchangeably $[3,15]$.

Based on the Monroe-Kelly hypothesis, the total volume of brain parenchyma, CSF, and intracranial blood should remain stable in the noncollapsible skull $[3,17]$. Consequently, as a compensatory mechanism, spinal CSF leakage could be accompanied by increased CSF volume, which accounts for subdural collections, or increased vascular volume, which accounts for venous engorgement, pituitary hyperemia, and pachymeningeal enhancement [3, 17]. In particular, the latter has been attributed to the compensatory dilation of dural veins and the loosening of the dural tight junctions resulting in the diffusion of the gadolinium in the microenvironment [2]. Downward displacement of the brain results from the loss of the buoyancy of the CSF [3].

Headache may be caused by the subsequent traction of the pain-sensitive dura, formation of subdural collections, or even hematomas due to the rupture of bridging veins $[1,11,18]$. Auditory or vestibular symptoms could be attributed to altered intralabyrinthine pressure or stretching of cochlear and vestibular verves $[2,3,19]$. Diplopia may occur due to III, IV, or more frequently VI stretching, whereas dysgeusia could manifest due to stretching of the chord of tympanum or glossopharyngeal nerve $[11,15]$. Reduced velocity of venous blood flow because of SIH could also result in venous thrombosis [20], while pituitary impairment may be caused by the pituitary stalk traction [21].

\section{Clinical presentation}

SIH classically presents with postural (also termed as orthostatic) headache, which develops or worsens in the upright position and significantly improves or is even completely relieved in recumbent position after seconds or minutes [1]. Predominant associated symptoms include nausea and vomiting, which are described in approximately half of cases [1, 3, 22]. Neck pain and stiffness, photophobia, and phonophobia may also often appear due to meningeal irritation [11]. Other accompanying features involve vertigo, tinnitus, visual disturbances such as blurred vision or bitemporal hemianopia, dysgeusia, hearing loss, gait ataxia, radicular arm pain, and cranial nerve deficits, such as diplopia, most frequently due to VI palsy, facial weakness, or numbness $[1,2,7,11,23-25]$. Although much rarer, cognitive decline [26], parkinsonism [27], chorea [28], quadriplegia [29], seizures [2], Meniere-like syndrome [30], hyperprolactinemia, and galactorrhea [3], as well as positional loss of consciousness and coma due to diencephalic herniation [31], have been also reported. In rare cases, focal back pain may reveal the site of CSF leakage [11].

Onset of headache is usually insidious, but acute or even thunderclap-like cases have been described, in which subarachnoid hemorrhage should be excluded [3]. Headache can be focal or generalized, bilaterally located in the occipital region $[3,11]$, and may be throbbing or more commonly non-throbbing [3, 7, 15]. Headache often worsens with Valsava maneuver, jugular vein compression, head movement, or coughing [29, 32]. Its severity is highly variable, and mild cases may remain undiagnosed [11]. However, lack of positional headache or atypical presentations should not rule out $\mathrm{SIH}$, since the inverse condition (worsening of headache when lying down) [33], chronic persistent headache especially in cases with delayed diagnosis [1,33], intermittent and non-related to position [34, 35], exertional headache [3], unilateral headache, or even the absence of headache have been also observed [7, 33, 36].

\section{Work-up and neuroimaging findings}

Initially, brain $\mathrm{CT}$ is recommended in emergency settings, since it may easily exclude other causes of headache or show subdural hematomas, cistern effacement, and collapse of the ventricles [1]. Then, if SIH is clinically suspected, brain and spinal MRI with and without gadolinium are the imaging methods of choice [3, 37].

Although non-specific, diffuse pachemeningeal enhancement in both supra- and infratentorial compartments, as well as subdural hygromas, are the most typical brain MRI findings of the condition [1,7], on the contrary to other meningeal pathologies, pachemeningeal enhancement tend to be more symmetrical, liner and thick [2]. Reduced size of cisterns and ventricles, subdural haematomas, pituitary enlargement mainly due to reactive hyperemia, venous engorgement, optic chiasm bowing, and increased anterior-posterior diameter of the brainstem are also indicative of SIH [7, 11]. Downward brain displacement- "sagging" of the brainand cerebellar tonsillar herniation may be also seen, mimicking Chiari I malformation $[1,11]$. As time passes, MRI findings tend to be less evident, and one out of three to five patients may actually have normal brain MRI scans $[1,38]$.

Spinal MRI may reveal the location of CSF leak, although with a lower sensitivity than CT myelography [1]. Sometimes, multiple sites of CSF leaks are identified [3]. Indicative signs include epidural effusions, dilated intradural veins, and dural enhancement diffusely or focally at the site of leakage, most commonly in the cervical and thoracic region [2, 23, 39]. Interestingly, the "floating dural sac sign," which is a hyperintense rim or band around the dural sac on axial spinal T2-weighted MRI images, has been proposed as a sensitive sign of CSF leakage (sensitivity and specificity 93\%) [40].

In case of high clinical suspicion and nondiagnostic spine MRI, CT myelography or the more complex but more sensitive intrathecal gadolinium 
MR myelography may detect the exact site of CSF leakage [41]. However, even these techniques may miss CSF leakage in about $30 \%$ of patients suspected for SIH [41]. Possible reasons may involve intermittent or too little leakage that does not reach the identification threshold of current techniques [42]. Finally, radionuclide cisternography is currently rarely used, because of its poor spatial resolution [1, 2, 43].

Lumbar puncture is also an integral part of the evaluation of SIH, since opening CSF pressure $<6 \mathrm{~cm} \mathrm{H}_{2} \mathrm{O}$ is considered diagnostic in clinically suspected patients, and may help in differential diagnosis especially regarding CNS infection or subarachnoid hemorrhage [7]. "Dry tap" or even negative CSF pressure may be also detected [3], and many patients display normal values [3]. In some cases, pleocytosis (primarily lymphocytic), elevated protein, or even xanthochromia can be seen in the CSF, due to dell diapidesis and protein leakage $[2,3,11]$. However, if MRI findings are highly indicative of SIH, lumbar puncture may be unnecessary-given the fact that normal CSF pressure does not exclude the diagnosis-and could actually worsen the symptomatology [7].

\section{Diagnosis}

$\mathrm{SIH}$ diagnosis is based on the combined evaluation of medical history, clinical presentation, neuroimaging data, and CSF pressure obtained by lumbar puncture (if necessary) [1]. According to International Classification of Headache Disorders (ICHD)-3 criteria, diagnosis of SIH requires the headache having developed in temporal relation to low CSF pressure $\left(<6 \mathrm{~cm} \mathrm{H}_{2} 0\right)$ and/or evidence of CSF leakage on imaging, not better accounted for by another ICHD-3 diagnosis, in addition to the absence of a procedure known to cause CSF leakage [44].

Given its variable clinical spectrum, the possible absence of classical neuroimaging findings, and even the potential normal CSF opening pressure, diagnosis of SIH can be challenging. In addition, the inadequate awareness of this condition may also contribute to the high rates of its wrong and delayed diagnosis [22].

Depending on each case, differential diagnosis may include subarachnoid hemorrhage, venous sinus thrombosis, carotid or vertebral artery dissection, subdural hematomas [1], infectious or carcinomatous meningitis, neurosarcoidosis [25], benign intracranial hypertension, colloid cysts of the third ventricle [15], posttraumatic headache, new daily persistent headache [3], and postural orthostatic tachycardia syndrome [7].

\section{Treatment options}

Currently, there are still insufficient data and randomized clinical trials supporting the optimal therapeutic strategy for $\mathrm{SIH}[1,45]$. Therefore, treatment decisions are individualized and they are primarily based on clinical observations [1]. In many patients, SIH resolves usually within days, following conservative management with bed rest, hydration, and NSAIDs [7]. Response to oral or intravenous caffeine and theophylline has been shown to be largely unpredictable [15]. Spontaneous resolution of $\mathrm{SIH}$ and healing of the dural tear have been also reported [2].

In regard to corticosteroids, their use in SIH still remains debated [1]. Oral corticosteroids have been proven beneficial in some SIH cases. In particular, an unsuccessful trial of oral fluorocortisone $(0.3 \mathrm{mg} /$ day $)$, followed by rapid response to intramuscular dexamethasone $(20 \mathrm{mg} /$ day), has been described in a patient, accompanied by normalization of CT brain findings 3 months later [46]. Psychotic symptomatology as a side-effect developed in this case, which resolved after corticosteroid cessation [46]. Although EBP failed to alleviate symptoms in another patient, oral prednisolone $(40 \mathrm{mg} /$ day) was finally beneficial [47]. Another three SIH cases treated successfully with oral prednisone (50 mg/day) [48] have also been reported. Resolution of headache and associated symptoms were noticed within 2-4 weeks, while gradual disappearance of abnormal MRI findings was observed within 6-12 months in this case-series [48]. No major side-effects have been reported, and corticosteroid treatment was well-tolerated [48]. Clinical improvement has also been described after oral fludrocortisone (1 case) [49], prednisolone (40 mg/day, 1 case) [50], and prednisone (50 mg/day, 2 cases) [51]. Four out of eight SIH patients have been also clinically improved following treatment with oral prednisone $(0.75 \mathrm{mg} / \mathrm{kg} /$ day $)$ [52] Oral prednisone $(80 \mathrm{mg} /$ day) also led to a rapid (within four hours) relief of postural headache in a pregnant woman with $\mathrm{SIH}$ [53]. Another interesting case-report indicated that oral prednisone $(80 \mathrm{mg} /$ day $)$ was associated with clinical and neuroimaging resolution of $\mathrm{SIH}$, manifested with reversible frontotemporal dementia [54]. A case of a patient with improvement after corticosteroid administration and deterioration after dexamethasone reduction has been also described, implying steroiddependency [21]. Excellent and rapid (within a day) response to intravenous methylprednisolone administration (40 $\mathrm{mg} / 8 \mathrm{~h}$ ) has been reported in another patient, followed by normalization of brain MRI findings 9 days later [55]. Intravenous dexamethasone $(13.2 \mathrm{mg} /$ day $)$ has been shown to rapidly (within a day) improve the level of consciousness of a comatose patient with $\mathrm{SIH}$, accompanying with resolution of brain MRI findings and epidural collection in the lumbrosacral region [56]. Postural headache has been also shown to resolve after intravenous steroids in another patient with SIH, while the site of CSF leakage could not be identified [57]. However, there is also evidence showing no benefit in $\mathrm{SIH}$ from corticosteroid treatment $[5,58]$. 
The pathophysiological mechanisms underlying the potential efficacy of corticosteroids in SIH are not fully elucidated [21]. Experimental evidence has demonstrated that steroids do not affect CSF production [59]. It has been hypothesized that corticosteroids may mediate the re-establishment of the loosened dural tight junctions, as indicated in vasogenic edema [21]. Enhanced fluid retention, inhibition of meningeal inflammatory responses, and improvement of brain edema have been also proposed as underlying mechanisms [56]. Suppression of CSF hyperabsorption or increased reabsorption of the CSF from the epidural space has been also suggested $[48,56]$, whereas data confirming any of these speculations are lacking.

In persistent or severe cases, autologous epidural blood patch (EBP) is currently the first-line treatment strategy for SIH [1], although its reported efficacy varies widely between 30 and 90\% [7, 38, 60]. EBP procedure involves the injection of patient's venous blood into the epidural space under aseptic conditions, resulting in blood clot formation that closes the dural hole [1]. EBPs can be delivered either directly to the specific site of the leakage under fluoroscopic or CT guidance (targeted) or away from the leakage site in cases where its specific location cannot be identified (blind) [1, 61]. A recent retrospective study indicated that two-site blind EBPs and targeted EBPs had comparable efficacy for symptom relief in SIH [62]. In many cases, multiple EBPs are required, and a cumulative effect characterized by partial improvement after each EBP delivery has been also observed [62]. Rare but possible complications of EBPs include intracranial hypertension, infectious or chemical meningitis, aseptic arachnoiditis, cauda equina syndrome, facial nerve palsy, pneumocephalus, subarachnoid hemorrhage, subdural hematoma, and intraspinal and intracerebral hemorrhage among others $[1,6,63-$ 66]. Continuous intrathecal or epidural saline infusion and epidural injection of fibrin glue have also been tried with varying responses $[2,11]$.

Surgical repair is another approach limited to refractory cases with a clearly identified CSF leakage [1, 7 , 67]. Various techniques have been tried with varying results, including duroplasty, ligation with sutures or metal aneurysm clips, or even intradural exploration, depending on the anatomy of dural defects [1$3,7,68]$. After surgical correction, intracranial hypertension as a rebound phenomenon may occur, and acetazolamide has been effective in some of these cases [69].

Subdural collections are usually thin and bilateral and do not usually cause significant mass effect $[2,11]$. Subdural hematomas occur in $10-25 \%$ of SIH cases, and surgical evacuation may be required if they are associated with mass effect or clinical deterioration [2]. Other rarer complications include superficial siderosis and bibrachial amyotrophy [15].

In most cases, SIH has a benign clinical course [3, 37]. After successful therapy, improvement of symptoms is expected instantaneously or usually within hours or days and often precedes the resolution of neuroimaging abnormalities, which is observed within days to weeks or months [3]. Recurrent headache may be due to recurrent CSF leakage (reported in about $10 \%$ of cases [32]), rebound intracranial hypertension, subdural hematoma, or venous sinus thrombosis, requiring further investigation [3]. Although follow-up evidence is scarce, an excellent prognosis has been observed in cases with an abnormal brain MRI and a single CSF leakage [3].

\section{Discussion of our case}

The main presenting complains of our patient were positional non-throbbing headache predominantly at the occipital region associated with nausea, which have been reported as the most frequent manifestations of SIH in the literature. No signs of connective tissue disorder were identified. After a brief unsuccessful trial of bed rest, hydration, and paracetamol treatment, a high-dose intravenous methylprednisolone therapy was administered. Her symptoms resolved within the first day. At the follow-up 1 month later, the patient was still asymptomatic. To the best of our knowledge, it is the first reported $\mathrm{SIH}$ case successfully treated with high-dose intravenous methylprednisolone (500 mg/day). Our patient's dramatic and rapid response to intravenous corticosteroids, with a clear temporal relationship between therapy initiation and clinical improvement, supports the potential use of brief high-dose intravenous corticosteroids in SIH. However, an important limitation of our case report is the absence of a neuroimaging followup, which might have confirmed the normalization of SIH MRI findings.

Given the limited consensus on $\mathrm{SIH}$ treatment, further research is required towards this direction. Currently, the use of corticosteroids as a first-line therapeutic option for SIH is far from well-established $[1,55]$. By presenting our case, we emphasize that a brief high-dose intravenous corticosteroid therapy could be considered as a treatment option in selected immunocompetent $\mathrm{SIH}$ cases, refractory to initial supportive management, before trying EBP or surgery. These invasive procedures require a well-experienced medical team, and they may be accompanied by postoperative morbidity and severe side-effects as aforementioned. The avoidance of longterm oral corticosteroid treatment could also minimize the potentially serious long-term side-effects, including immunosuppression, osteoporosis, weight gain, steroid- 
induced myopathy, cataract, and glaucoma among others. However, since acute psychotic symptoms may develop in patients receiving high doses of corticosteroids, caution is recommended especially in patients with psychiatric disorders [70]. In combination to the clinical experience reported by others, we suggest that this treatment approach should be investigated in future randomized clinical trials, in comparison to conservative management and EBPs.

\section{Conclusions}

$\mathrm{SIH}$ is an underdiagnosed condition, where optimal management is still controversial. Our case, combined with evidence from the literature, supports the highdose intravenous corticosteroid administration as a reasonable treatment option in cases refractory to conservative management, before trying epidural blood patches or surgical repair. Randomized clinical trials are needed towards this direction, in order to optimize SIH patients' outcomes.

\section{Abbreviations}

CSF: Cerebrospinal fluid; CMV: Cytomegalovirus; CT: Computed tomography; EBV: Epstein-Barr virus; EPB: Epidural blood patch; HSV: Herpes simplex virus; ICHD: International Classification of Headache Disorders; IV: Intravenous: MRI: Magnetic resonance imaging; NSAIDs: Nonsteroidal anti-inflammatory drugs; SIH: Spontaneous intracranial hypotension; VZV: Varicella-zoster virus; WBC: White blood cell

\section{Acknowledgements}

Not applicable.

\section{Authors' contributions}

EA contributed to the clinical management of the patient and wrote the initial manuscript. EP contributed to the radiological diagnosis, provided the radiological images, and contributed to the writing of the initial manuscript. GZ contributed to the initial clinical management of the patient and contributed to the writing of initial manuscript. MR, LS, and VZ contributed to the clinical management of the patient and provided critical comments on the final manuscript. All authors read and approved the final manuscript.

\section{Funding}

No funding source was used.

\section{Availability of data and materials}

Not applicable

\section{Declarations}

\section{Ethics approval and consent to participate}

The study was conducted in accordance with the Helsinki Declaration of 1975, as revised in 2008

\section{Consent for publication}

Written informed consent was obtained from the patient for publication of this case report and accompanying images.

\section{Competing interests}

The authors declare that they have no competing interests.

\section{Author details}

'Department of Neurology, National and Kapodistrian University of Athens, Eginition Hospital, Leof. Vasilissis Sofias 72, 11528 Athens, Greece. ${ }^{2}$ Research Unit of Radiology, 2nd Department of Radiology, National and Kapodistrian University of Athens, Eginition Hospital, Athens, Greece.
Received: 2 December 2020 Accepted: 15 April 2021

Published online: 12 July 2021

\section{References}

1. Lin JP, Zhang SD, He FF, Liu MJ, Ma XX. The status of diagnosis and treatment to intracranial hypotension, including SIH. J Headache Pain. 2017; 18(1):4. https://doi.org/10.1186/s10194-016-0708-8.

2. Schick U, Musahl C, Papke K. Diagnostics and treatment of spontaneous intracranial hypotension. Minim Invasive Neurosurg. 2010:53(1):15-20. https://doi.org/10.1055/s-0030-1247552.

3. Schievink WI. Spontaneous spinal cerebrospinal fluid leaks and intracranial hypotension. JAMA. 2006;295(19):2286-96. https://doi.org/10.1001/jama.2 95.19.2286.

4. Podkovik S, et al. Spontaneous intracranial hypotension: case study and review of the literature. Cureus. 2020;12(2):e7018.

5. Vaidhyanath $\mathrm{R}$, et al. Spontaneous intracranial hypotension: a cause of severe acute headache. BMJ Case Rep. 2009;2009:bcr1120081207. https:// doi.org/10.1136/bcr.11.2008.1207

6. Pattichis AA, Slee M. CSF hypotension: a review of its manifestations, investigation and management. J Clin Neurosci. 2016;34:39-43. https://doi. org/10.1016/j.jocn.2016.07.002.

7. Upadhyaya P, Ailani J. A review of spontaneous intracranial hypotension Curr Neurol Neurosci Rep. 2019;19(5):22. https://doi.org/10.1007/s11910-0190938-7.

8. Schievink WI, Maya MM, Moser F, Tourje J, Torbati S. Frequency of spontaneous intracranial hypotension in the emergency department. J Headache Pain. 2007;8(6):325-8. https://doi.org/10.1007/s10194-007-0421-8.

9. Schievink WI, Gordon OK, Tourje J. Connective tissue disorders with spontaneous spinal cerebrospinal fluid leaks and intracranial hypotension: a prospective study. Neurosurgery. 2004:54(1):65-70; discussion 70-1. https:// doi.org/10.1227/01.NEU.0000097200.18478.7B

10. Reinstein E, Pariani M, Bannykh S, Rimoin DL, Schievink WI. Connective tissue spectrum abnormalities associated with spontaneous cerebrospinal fluid leaks: a prospective study. Eur J Hum Genet. 2013;21(4):386-90. https:// doi.org/10.1038/ejhg.2012.191.

11. Schievink WI. Spontaneous spinal cerebrospinal fluid leaks: a review. Neurosurg Focus. 2000:9(1):e8. https://doi.org/10.3171/foc.2000.9.1.8.

12. Schievink WI, Goseland A, Cunneen S. Bariatric surgery as a possible risk factor for spontaneous intracranial hypotension. Neurology. 2014;83(20): 1819-22. https://doi.org/10.1212/WNL.0000000000000985.

13. Fry RA, Perera A. Failure of repeated blood patch in the treatment of spinal headache. Anaesthesia. 1989;44(6):492-3. https://doi.org/10.1111/j.1365-2 044.1989.tb11378.x.

14. Graff-Radford SB, Schievink WI. High-pressure headaches, low-pressure syndromes, and CSF leaks: diagnosis and management. Headache. 2014; 54(2):394-401. https://doi.org/10.1111/head.12283.

15. Mokri B. Spontaneous low pressure, low CSF volume headaches: spontaneous CSF leaks. Headache. 2013;53(7):1034-53. https://doi.org/1 0.1111/head.12149.

16. Milledge JT, Ades LC, Cooper MG, Jaumees A, Onikul E. Severe spontaneous intracranial hypotension and Marfan syndrome in an adolescent. J Paediatr Child Health. 2005;41(1-2):68-71. https://doi.org/10.1111/j.1440-1754.2005.00541.x.

17. Fishman RA, Dillon WP. Dural enhancement and cerebral displacement secondary to intracranial hypotension. Neurology. 1993;43(3 Pt 1):609-11. https://doi.org/10.1212/WNL.43.3 Part_1.609.

18. Mokri B. Spontaneous cerebrospinal fluid leaks: from intracranial hypotension to cerebrospinal fluid hypovolemia--evolution of a concept Mayo Clin Proc. 1999;74(11):1113-23. https://doi.org/10.4065/74.11.1113.

19. Wang LP. Schmidt JF. Central nervous side effects after lumbar puncture. A review of the possible pathogenesis of the syndrome of postdural puncture headache and associated symptoms. Dan Med Bull. 1997:44(1):79-81.

20. Richard S, Kremer S, Lacour JC, Vespignani H, Boyer P, Ducrocq X. Cerebra venous thrombosis caused by spontaneous intracranial hypotension: two cases. Eur J Neurol. 2007;14(11):1296-8. https://doi.org/10.1111/j.1468-1331.2 007.01947.x

21. Platz J, Glücker T, Gratzl O, Woydt M. Spontaneous intracranial hypotension: case report with subdural hematomas, steroid dependency and clinical improvement after myelography. Zentralbl Neurochir. 2007:68(2):87-90. https://doi.org/10.1055/s-2007-977738.

22. Schievink WI. Misdiagnosis of spontaneous intracranial hypotension. Arch Neurol. 2003;60(12):1713-8. https://doi.org/10.1001/archneur.60.12.1713. 
23. He FF, Li L, Liu MJ, Zhong TD, Zhang QW, Fang XM. Targeted epidural blood patch treatment for refractory spontaneous intracranial hypotension in China. J Neurol Surg B Skull Base. 2018;79(3):217-23. https://doi.org/10.1 055/s-0037-1606312.

24. Frank LR, Paxson A, Brake J. Spontaneous intracranial hypotension--a case report. J Emerg Med. 2005;28(4):427-30. https://doi.org/10.1016/j.jemermed.2 004.11.024.

25. Ferrante E, Savino A, Sances G, Nappi G. Spontaneous intracranial hypotension syndrome: report of twelve cases. Headache. 2004;44(6):61522. https://doi.org/10.1111/j.1526-4610.2004.446012.x

26. Wicklund MR, Mokri B, Drubach DA, Boeve BF, Parisi JE, Josephs KA. Frontotemporal brain sagging syndrome: an SIH-like presentation mimicking FTD. Neurology. 2011;76(16):1377-82. https://doi.org/10.1212/ WNL.0b013e3182166e42

27. Tian W, Zhang J, Chen J, Liu Y, Chen X, Wang N. A quantitative study of intracranial hypotensive syndrome by magnetic resonance. Clin Neurol Neurosurg. 2016;141:71-6. https://doi.org/10.1016/j. clineuro.2015.12.014.

28. Mokri B, Ahlskog JE, Luetmer PH. Chorea as a manifestation of spontaneous CSF leak. Neurology. 2006;67(8):1490-1. https://doi.org/10.1212/01.wnl. 0000240059.96502.bf.

29. Maurya VK, Ravikumar R, Bhatia M, Sirohi YS. Intracranial hypotension: an uncommon entity with common presentation. Med J Armed Forces India. 2017;73(2):188-96. https://doi.org/10.1016/j.mjafi.2016.11.012.

30. Portier F, de Minteguiaga C, Ba Huy PT, Racy E, Herman P. Spontaneous intracranial hypotension: a rare cause of labyrinthine hydrops. Ann Otol Rhinol Laryngol. 2002;111(9):817-20. https://doi.org/10.1177/0003489402111 00910.

31. Lagrand TJ, Beukers R. Sagging brain causing postural loss of consciousness: a case of severe spontaneous intracranial hypotension. Pract Neurol. 2015;15(6):471-3. https://doi.org/10.1136/ practneurol-2015-001183.

32. Lahoria R, Allport L, Glenn D, Masters L, Shnier R, Davies M, et al. Spontaneous low pressure headache - a review and illustrative patient. J Clin Neurosci. 2012;19(8):1076-9. https://doi.org/10.1016/j. jocn.2011.12.014

33. Mokri B, Aksamit AJ, Atkinson JL. Paradoxical postural headaches in cerebrospinal fluid leaks. Cephalalgia. 2004;24(10):883-7. https://doi.org/1 0.1111/j.1468-2982.2004.00763.x

34. Mokri B. Spontaneous intracranial hypotension. Curr Neurol Neurosci Rep. 2001;1(2):109-17. https://doi.org/10.1007/s11910-001-0005-y.

35. Schievink WI, Smith KA. Nonpositional headache caused by spontaneous intracranial hypotension. Neurology. 1998;51(6):1768-9. https://doi.org/1 0.1212/WNL.51.6.1768.

36. Mokri B, Atkinson JL, Piepgras DG. Absent headache despite CSF volume depletion (intracranial hypotension). Neurology. 2000;55(11):1722-4. https:// doi.org/10.1212/WNL.55.11.1722.

37. Tyree TL, Porter R. Spontaneous intracranial hypotension: a case study. J Am Acad Nurse Pract. 2012;24(5):286-9. https://doi.org/10.1111/j.1745-7599.2012. 00741.x.

38. Schievink WI, Dodick DW, Mokri B, Silberstein S, Bousser MG, Goadsby PJ. Diagnostic criteria for headache due to spontaneous intracranial hypotension: a perspective. Headache. 2011;51(9):1442-4. https://doi.org/1 0.1111/j.1526-4610.2011.01911.x.

39. Dillon WP. Spinal manifestations of intracranial hypotension. AJNR Am Neuroradiol. 2001;22(7):1233-4.

40. Hosoya $T$, et al. Floating dural sac sign is a sensitive magnetic resonance imaging finding of spinal cerebrospinal fluid leakage. Neurol Med Chi (Tokyo). 2013;53(4):207-12. https://doi.org/10.2176/nmc.53.207.

41. Akbar JJ, Luetmer PH, Schwartz KM, Hunt CH, Diehn FE, Eckel LJ. The role of MR myelography with intrathecal gadolinium in localization of spinal CSF leaks in patients with spontaneous intracranial hypotension. AJNR Am J Neuroradiol. 2012;33(3):535-40. https://doi.org/10.3174/a jnr.A2815.

42. Schievink WI, Schwartz MS, Maya MM, Moser FG, Rozen TD. Lack of causal association between spontaneous intracranial hypotension and cranial cerebrospinal fluid leaks. J Neurosurg. 2012;116(4):749-54. https://doi.org/1 0.3171/2011.12.JNS111474

43. Weber WE, Heidendal GA, de Krom MC. Primary intracranial hypotension and abnormal radionuclide cisternography. Report of a case and review of the literature. Clin Neurol Neurosurg. 1991;93(1):55-60. https://doi.org/10.1 016/0303-8467(91)90010-M.

44. Headache Classification Committee of the International Headache, S. The International Classification of Headache Disorders, 3rd edition (beta version). Cephalalgia. 2013;33(9):629-808.

45. O'Brien $\mathrm{M}$, et al. Spontaneous intracranial hypotension: case reports and literature review. Ir J Med Sci. 2012;181(2):171-7. https://doi.org/10.1007/s11 845-011-0766-5.

46. Murros K, Fogelholm R. Spontaneous intracranial hypotension with slit ventricles. J Neurol Neurosurg Psychiatry. 1983;46(12):1149-51. https://doi. org/10.1136/jnnp.46.12.1149.

47. Sakajiri K, Ohtaki M, Yoshinaga T, Uchiyama S. Case of intracranial hypotension responsive to oral prednisolone. Rinsho Shinkeigaku. 2006; 46(6):395-9.

48. Gentile S, Giudice RL, Martino PD, Rainero I, Pinessi L. Headache attributed to spontaneous low CSF pressure: report of three cases responsive to corticosteroids. Eur J Neurol. 2004;11(12):849-51. https://doi.org/10.1111/j.14 68-1331.2004.00898.x.

49. Rizk M, Khatib ME, Yamout B, Hujeily E, Ayoub S, Ayoub C, et al. Spontaneous intracranial hypotension syndrome treated with fludrocortisone. A A Case Rep. 2015;4(1):8-11. https://doi.org/10.1213/XAA. 0000000000000105 .

50. Arai M. Spontaneous intracranial hypotension with extensive epidural fluid collection in the spine: a case improved with steroid therapy. Rinsho Shinkeigaku. 2010;50(1):31-3. https://doi.org/10.5692/clinica Ineurol.50.31.

51. Russo C, Buono V, Fenza G, Zandolino A, Serino A, Manto A. Spontaneous intracranial hypotension: two steroid-responsive cases. Pol J Radiol. 2018;83: e229-33. https://doi.org/10.5114/pjr.2018.76380.

52. Hannerz J, Dahlgren G, Irestedt L, Meyerson B, Ericson K. Treatment of idiopathic intracranial hypotension: cervicothoracic and lumbar blood patch and peroral steroid treatment. Headache. 2006:46(3):508-11. https://doi. org/10.1111/j.1526-4610.2006.00383.x

53. Hashmi M. Low-pressure headache presenting in early pregnancy with dramatic response to glucocorticoids: a case report. J Med Case Rep. 2014; 8(1):115. https://doi.org/10.1186/1752-1947-8-115.

54. Hong M, Shah GV, Adams KM, Turner RS, Foster NL. Spontaneous intracranial hypotension causing reversible frontotemporal dementia. Neurology. 2002;58(8):1285-7. https://doi.org/10.1212/ WNL.58.8.1285.

55. Pascual LF, Santos S, Escalza I, Iniguez C, Morales-Asin F. Spontaneous intracranial hypotension: quick clinical and magnetic resonance imaging response to corticosteroids. A case report. Headache. 2002;42(5):359-61. https://doi.org/10.1046/j.1526-4610.2002.02108.x.

56. Goto S, Ohshima T, Yamamoto T, Shimato S, Nishizawa T, Kato K. Successful steroid treatment of coma induced by severe spontaneous intracranial hypotension. Nagoya J Med Sci. 2016;78(2):229-36.

57. Oshiro S, Fukushima T. Spontaneous intracranial hypotension manifesting as sudden deafness followed by chronic subdural hematoma. No To Shinkei. 2003;55(9):801-5.

58. Pannullo SC, Reich JB, Krol G, Deck MDF, Posner JB. MRI changes in intracranial hypotension. Neurology. 1993;43(5):919-26. https://doi.org/1 0.1212/WNL.43.5.919.

59. Vela AR, Carey ME, Thompson BM. Further data on the acute effect of intravenous steroids on canine CSF secretion and absorption. J Neurosurg. 1979;50(4):477-82. https://doi.org/10.3171/jns.1979.50.4.0477.

60. Wu JW, Hseu SS, Fuh JL, Lirng JF, Wang YF, Chen WT, et al. Factors predicting response to the first epidural blood patch in spontaneous intracranial hypotension. Brain. 2017;140(2):344-52. https://doi.org/10.1093/ brain/aww328.

61. Smith KA. Spontaneous intracranial hypotension: Targeted or blind blood patch. J Clin Neurosci. 2016;25:10-2. https://doi.org/10.1016/j.jocn.2015.07. 009.

62. Ahn C, Lee E, Lee JW, Chee CG, Kang Y, Kang HS. Two-site blind epidural blood patch versus targeted epidural blood patch in spontaneous intracranial hypotension. J Clin Neurosci. 2019;62:147-54. https://doi.org/10.1 016/j.jocn.2018.11.039

63. Taivainen $T$, et al. Efficacy of epidural blood patch for postdural puncture headache. Acta Anaesthesiol Scand. 1993;37(7):702-5. https://doi.org/1 0.1111/j.1399-6576.1993.tb03793.x. 
64. Diaz JH. Permanent paraparesis and cauda equina syndrome after epidura blood patch for postdural puncture headache. Anesthesiology. 2002;96(6): 1515-7. https://doi.org/10.1097/00000542-200206000-00035.

65. Kawamata T, Omote K, Matsumoto M, Toriyabe M, Ito T, Namiki A. Pneumocephalus following an epidural blood patch. Acta Anaesthesiol Scand. 2003;47(7):907-9. https://doi.org/10.1034/j.13996576.2003.00165.x

66. Perez M, Olmos M, Garrido FJ. Facial nerve paralysis after epidural blood patch. Reg Anesth. 1993;18(3):196-8.

67. Farhat HI, Hood B, Vanni S, Levi AD. Minimally invasive repair of spontaneous intracranial hypotension. J Neurosurg. 2011;114(2):505-9. https://doi.org/10.3171/2010.8.JNS10412.

68. Cohen-Gadol AA, et al. Surgical anatomy of dural defects in spontaneous spinal cerebrospinal fluid leaks. Neurosurgery. 2006;58(4 Suppl 2):ONS-23845 discussion ONS-245.

69. Mokri B. Intracranial hypertension after treatment of spontaneous cerebrospinal fluid leaks. Mayo Clin Proc. 2002;77(11):1241-6. https://doi. org/10.4065/77.11.1241.

70. Stanbury RM, Graham EM. Systemic corticosteroid therapy--side effects and their management. Br J Ophthalmol. 1998;82(6):704-8. https://doi.org/10.113 6/bjo.82.6.704

\section{Publisher's Note}

Springer Nature remains neutral with regard to jurisdictional claims in published maps and institutional affiliations.

\section{Submit your manuscript to a SpringerOpen ${ }^{\circ}$ journal and benefit from:}

- Convenient online submission

- Rigorous peer review

- Open access: articles freely available online

High visibility within the field

- Retaining the copyright to your article

Submit your next manuscript at $\boldsymbol{\nabla}$ springeropen.com 